\title{
VIEWS ON THE TREATMENT OF VENEREAL DISEASE IN THE EARLY NINETEENTH CENTURY AS REFLECTED IN THE WRITINGS OF SAMUEL COOPER*
}

BY

\author{
R. R. WILLCOX
}

Samuel Cooper was born in 1780 into a family in easy circumstances. After serving an apprenticeship at St. Bartholomew's Hospital, London, he obtained his degree in 1803 and settled in Golden Square. In 1806 he won the Jacksonian Prize of the Royal College of Surgeons of England for the best essay on "Diseases of the Joints", and in 1807 , at the immature age of 27 , he wrote "The First Lines on the Practice of Surgery" which was to run into seven editions. He is better known for his other great work, the " Surgical Dictionary", which also ran into seven large editions.

In 1813 he joined the Army ; he served in Holland in 1814 and later at Waterloo, but, at the end of the war, he retired from the service to spend the succeeding years in the revision of his two major works. Meanwhile, his dictionary was being translated into French, German, and Italian, and was to achieve several American editions. Cooper was also not afraid to undertake the editorship of a textbook on medicine.

True recognition came somewhat late. He was asked to deliver the Hunterian Oration in 1834, having been elected to the surgical staff at University College Hospital three years earlier at the age of 51. He remained on the staff as Surgeon and Professor of Anatomy until his death. In 1845 he was elected President of the Royal College of Surgeons, and a year later a Fellow of the Royal Society. He died, allegedly of gout, on December 2, 1848.

Cooper's writings relating to the venereal diseases are of considerable interest, and since he made no personal contribution to the study of these conditions, they probably give a fair representation of the general medical opinion of his time.

SYPHILIS.-Cooper was a great respecter of John Hunter (1728-93), but it also seems that he

* Received for publication May 16, 1951. was more than dimly aware that the great man might have been wrong in some of his teachings concerning the venereal diseases. Cooper had been impressed by a book written by a Dublin surgeon, Richard Carmichael (1779-1849). This work, entitled "Observations on the Symptoms and Specific Distinctions of Venereal Diseases", which was published in 1818, was critical of many of Hunter's views. It says much for the prestige of that great man that, even a quarter of a century after his death, learned members of the profession would still apologize for presuming to disagree with his teachings. Cooper himself was very conscious of the strength of conservative opinion and, in the preface to his surgical textbook, wrote :

The Chapter on Syphilis contains a tolerably full account of the recent investigations concerning that perplexing disease; together with a summary of opinions espoused by Mr. Carmichael. Perhaps, a few determined adherents to the Hunterian doctrines, respecting lues venerea, will be inclined to censure me, for having assisted in the promulgation of the new observations on this unsettled and mysterious subject.

The chapter on syphilis is full and makes rather heavy reading, the lengthy sub-sections being: "General Observations", "Of True Chancres and Primary Sores", "Of Syphilitic and Other Buboes ", "Treatment of Buboes", "Secondary Symptoms "; "Venereal Sore Throat", " Nodes" (much more common then than now), "Venereal Ulcers in Consequence to the Absorption of Syphilitic Virus into the Constitution", and "Treatment of Secondary Symptoms"; these give some idea of its scope. Syphilitic iritis is described in the ophthalmic section, but syphilitic aortic aneurysms and neurosyphilis might be said not to exist, since the disease was regarded only as a succession of visible tissue-destroying episodes, and a "cure" consisted in the removal of clinical signs and symptoms. 
Syphilis was believed by Hunter to be due to a specific morbid poison which, once introduced into the body, produced a disposition to the disease so that, even if this were neutralized by an as yet undiscovered drug, cure would not result. As to the origin of the disease, he stated that, though the general opinion was that of Astruc who favoured the Columbian theory, he himself considered the evidence insufficient, and that, had the sailors of Columbus contracted syphilis at Otaheite, their genital organs would certainly have been destroyed on the return voyage - an indication of the virulence of the infection in those days. Cooper believed, too, as a result of the experiments of Benjamin Bell, and against Hunter, that gonorrhoea and syphilis were separate diseases. It was also evident to him that all patients with penile sores did not develop constitutional symptoms.

Cooper also believed that mercury was valuable for primary and especially for secondary syphilis, but that the cases should be selected with care and the drug never used in the presence of phagedena. At the same time, however, he accumulated much evidence to show that syphilis could be "cured" without mercury, which many held in disfavour. He reported that Mr. Rose, Surgeon to the Regiment of Coldstream Guards in London, treated all his military patients with genital ulcers without mercury, and all with constitutional symptoms likewise. The same plan was adopted in the hospital of the Second Battalion of the Third Regiment of Guards at Windsor. The Germans serving with the British in the recent war against Napoleon were also disbelievers in the use of mercury, and in Russia, when a vacancy for a surgeon occurred in a large venereal diseases hospital, there was an agitated and heated discussion whether or not the appointment should be given to a mercury enthusiast. With regard to the Peninsular War, Cooper noted that the use of mercury had been generally abandoned in Portugal, where for some years syphilis had become much milder, and that reliance was placed solely on topical applications. However, the venereal diseases proved particularly severe in the British soldiery serving in that area.

GonORRHOEA.-This disease was at last emerging as an entity, and its tendency to spontaneous cure was recognized. However, the treatment given was usually severe and often brutal, although for the early stages the recommendation that "linen soaked in saturnine lotion" be constantly applied to the parts, with the avoidance of spiritis and spices by mouth, was sound. After a few days, however, attempts were made to "alter the action of the vessels of the lining of the urethra so as to make them secrete again the healthy mucous fluid, with which the canal is naturally lubricated, instead of a purulent discharge". For this, " injections" of zinc sulphate of increasing concentration, commencing with five grains to four ounces of water, or oxymuriate of mercury, were used. These "injections" were performed two to three times daily.

Promising results were reported from the use of a spice from Java and China. This was cubebs, whose action, though Cooper was not unduly impressed by it, he likened to that of balsam of copaiba, in so far that with its use an initial improvement was frequently followed by a relapse. However, it was generally spoken of in the highest terms, the dose being a dessert-spoonful taken by mouth thrice daily.

A distressing but common complication was chordee, while prostatic involvement was probably responsible for many of the symptoms listed under the term "cystitis". For chordee, camphorated foments or friction with mercury dintment might be given, though leeches applied to the penis were considered proper, and that organ might also be subjected to the steam of hot water. For " cystitis " opiate clysters were used, as were warm baths and even phlebotomy "if the patient was young and robust". Leeches applied to the perineum were considered a suitable treatment, as was blistering in the same site.

GleET.-Urethritis, whether due to chronic gonorrhoea or to a then unknown cause, was called "gleet". This was regarded as a noninfectious discharge in which the globules were blended with mucous secretion, whereas in gonorrhoea the globules were mixed with serous fluid. For this condition, as indeed to-day, treatments were manifold. Prolonged treatment with " injections" (urethral syringings) was much favoured to alter the action of the vessels, while the use of bougies, 4 to 5 inches long and medicated with camphor or turpentine, was going out of fashion. Cold baths, preferably in the sea, were also approved as were rough horse exercises. In certain cases electricity and even blisters to the skin beneath the urethra were applied. If the patient was debilitated, cinchona bark or a decoction of steel filings was recommended.

STRICTURE.-Urethral stricture as a cause of gleet was well recognized. Hunter, who grouped urethral stricture with the other recognized strictures of the oesophagus, rectum, prepuce, and lacrimal duct, did not believe gonorrhoea to be the primary cause. Nor did he credit the view that strictures 


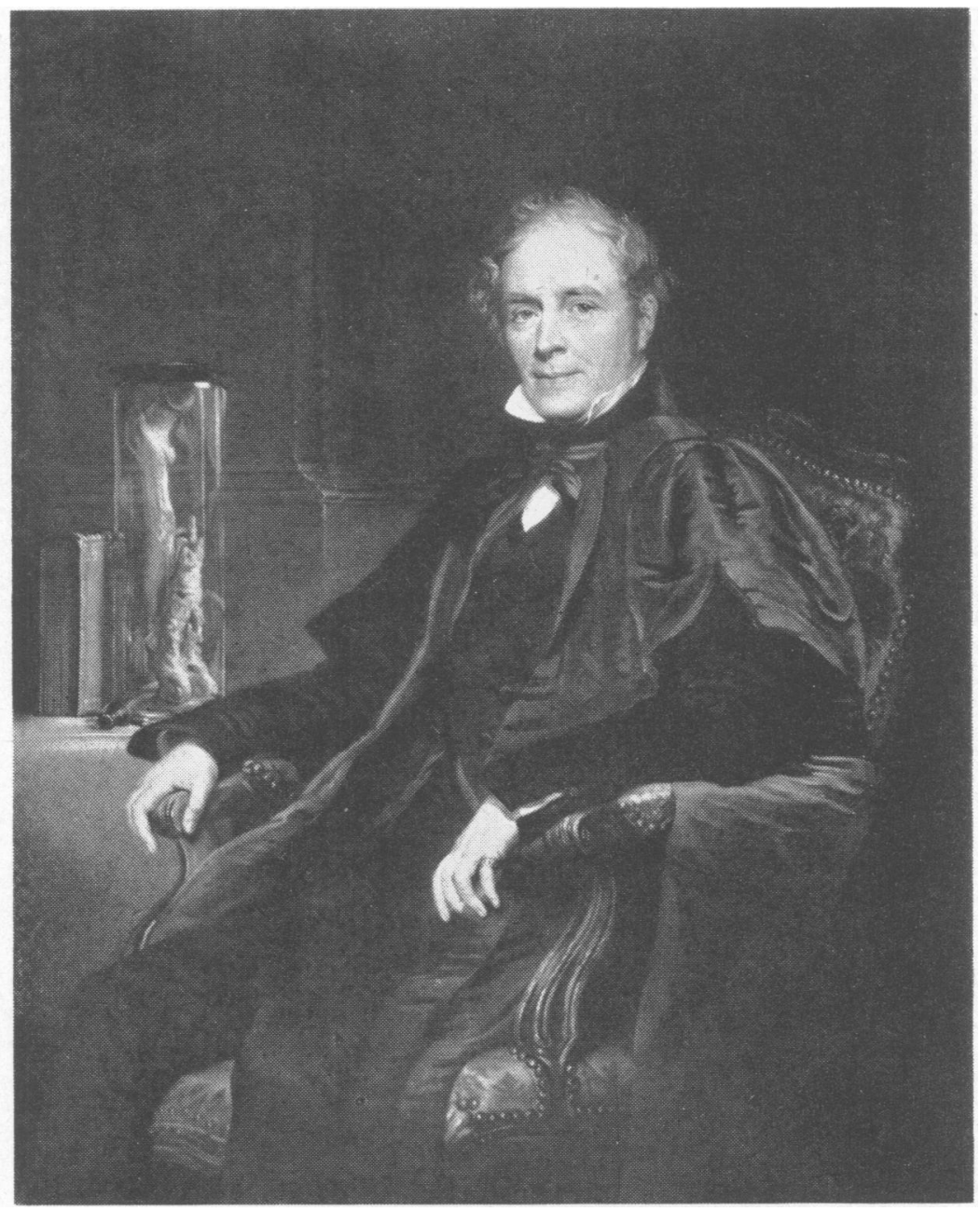

SAMUEL COOPER

From the mezzotint by H. Cousins after A. Morton (Picture in the Royal College of Surgeons)-engraving in the Wellcome Collection.

were usually brought about by the use of " injections", though Cooper, who himself remained impartial, stated that by 1820 many surgeons were incriminating both gonorrhoea and its treatment as responsible for their production.

Treatment usually involved the common bougie of which various forms were available. With characteristic understatement Cooper says :

In introducing any instrument properly into the urethra, some degree of skill is displayed.

A table is appended, credited in the text to Sir Everard Home, Hunter's brother-in-law, showing the diameters obtained from waxen casts of the different parts of the male urethra at the ages of 80 and 30.

It is stated that a knowledge of the extent of the stricture would be invaluable if it could be obtained, for

... no surgeon, knowing that the obstruction and the disease extend far along the urethra, would ever in such a case give preference to the employment of armed bougies. Those armed with the nitrate of silver, could never be expected to burn their way through a stricture an inch in length.

Charles Bell used ball probes consisting of small silver and gold balls mounted on metal sticks, which 
were passed through the stricture to ascertain its length.

The bougie was "armed" as follows. It was first passed up to the obstruction, and its surface scratched by the finger-nail at the point of emergence at the meatus. This gave the position of the stricture. A small hole, about one-sixteenth of an inch deep, was next made in the rounded end of the extremity of the bougie and a minute piece of caustic (caustic potash was often used), about the size of a pin's head, was pushed into the hole with a pin and covered with hog's lard. The bougie was then inserted to the same length as before when, after a pause while the lard was dissolved, it was thrust forward an eighth of an inch at a time. An English visitor to Paris described how, in La Charité hospital there, silver catheters were often forced into the biadder " in spite of all opposition ". However, extravasation of urine seemed to be a frequent complication and there were fatalities. At this time, too, a Dr. Arnott invented a dilator with a tube of oiled silk which, after insertion through the stricture, could be distended by air or water.

Thus the venereal diseases at the time of Waterloo seem to have been only for the stalwart. The lot of the nervous person must have been particularly distressing both from fear of the disease itself and from the treatments then in vogue.

Grateful acknowledgments are expressed to the Wellcome Historical Medical Museum for kindly providing a copy of Morton's portrait of Cooper.

\section{REFERENCES}

Bettany, G. T. (1887). Dictionary of National Biography, vol. 12, p. 148 ; vol. 9, p.131. Smith, Elder and Co., London.

Cooper, S. (1819, 1820). "First Lines of the Practice of Surgery ", 4th ed., 2 vols. Longman, Hurst, Reed, Orme, and Brown, London. 